\title{
Eventos Culturais como estratégia de fomento do turismo: análise do Festival Folclórico de Parintins (AM)
}

\section{Cultural events as a strategy of tourism promotion: analysis of Folkloric Festival of Parintins (AM, Brazil)}

\author{
José Jailson Medeiros de Melo, Ana Paula Araújo-Maciel', \\ Silvio José de Lima Figueiredo
}

\begin{abstract}
RESUMO
Vislumbrando a necessidade de estudos que façam abordagem crítica a respeito da contribuição dos eventos para o desenvolvimento das localidades turísticas no Brasil, julga-se necessária a produção de trabalhos dessa natureza. Dessa forma, o presente artigo objetiva analisar os eventos como estratégia de desenvolvimento dos destinos turísticos. A metodologia foi caracterizada como exploratória, uma vez que busca e mostra de que forma os eventos podem contribuir para o desenvolvimento do turismo nos destinos sedes, utilizou-se a abordagem teórica do tema, a partir de textos em periódicos nacionais e internacionais e livros sobre o tema pesquisado, além de analise documental, respaldando os resultados apresentados no trabalho. Finalmente, percebeu-se que os eventos contribuem para o desenvolvimento local e do turismo, dadas as suas características de consumo do espaço turístico e fomento socioeconômico. Possuem elementos fundamentais para o desenvolvimento de uma localidade como: a atração de investimentos, promoção do turismo, ações urbanas, e parcerias público-privadas, como o caso do Festival Folclórico de Parintins.
\end{abstract}

PALAVRAS-CHAVE: Turismo; Eventos; Eventos Culturais; Desenvolvimento Local; Destinos.

\section{ABSTRACT}

Envisaging the need for studies which have critical approach regarding the contribution of events for the development of tourist locations in Brazil, it is considered necessary to produce work of this nature. Thus, this article aims to analyze the events as a development strategy of tourism destinations. The methodology was characterized as exploratory, since it searches and shows how events can contribute to the development of tourism in the destinations headquarters, it used the theoretical approach of the subject, from texts in national and international journals and books on the topic researched, and documentary analysis, supporting the results presented in the study. Finally, it was realized that events contribute to local development and tourism, given their consumption characteristics of the tourist space and socioeconomic incentives. They have key elements for the development of a locality as: attracting investment, promoting tourism, urban actions, and public-private partnerships, such as the case of Parintins Folklore Festival.

KEYWORDS: Tourism; Events; Cultural Events; Local Development; Destinations. 


\section{Introdução}

À primeira vista, testemunhar a cultura de localidades do interior do Brasil significa a observação da diversidade de formas com as quais esses padrões culturais se manifestam. Se a cultura aparece como festa ligada ou não a religiões populares, isso quer dizer que necessariamente tem-se a configuração do acontecimento cultural, do evento cultural, do festival. Nesse caso, o encontro espaço-temporal entre pessoas com objetivos específicos pré-destinados diz respeito a objetivos relacionados ao festejar, brincar, e participar do êxtase coletivo que caracteriza a festa pública e coletiva, o sagrado e o conceito de comunidade.

O ajuntamento e as relações face-a-face proporcionadas pelo encontro no processo das relações sociais de indivíduos e grupos externos ao contexto da comunidade (visitantes) pressupõem também a necessidade de organizar essa recepção. Desse modo, o turismo se serve e apreende os eventos culturais festivos ao mesmo tempo em que torna possível a participação de um público maior nessas festas. Esse aspecto indica as profundas relações entre a festa e o turismo, e, portanto, entre o evento cultural e o turismo, juntamente com outros diversos eventos especiais relacionados a encontros das associações culturais e científicas, competições esportivas e outros.

O turismo tem se manifestado como atividade de cunho econômico e social para as localidades onde o mesmo se instala. Sua conjuntura proporciona se planejado de forma coerente, benefícios relevantes, porém pode também acarretar problemas de ordem social. De uma forma geral, a atividade turística tem tido destaque em todo mundo e no Brasil não tem sido diferente, apesar das poucas ações de planejamento que realmente lograram êxito, a atividade vem crescendo principalmente com o aumento do turismo interno e dos fluxos estrangeiros, proporcionando aos destinos maiores opções de desenvolvimento econômico e social.

Um dos aspectos que tem contribuído para o incremento de algumas localidades são os eventos culturais e festivais, que aqui são estudados enquanto possíveis promotores do desenvolvimento local e do turismo, e que para sua efetivação necessitam de infraestrutura específica, e têm como contrapartida promover benefícios à localidade receptora. Os eventos culturais e os festivais têm proporcionado aos destinos sedes a oportunidade de promover a atividade turística, tendo em vista que os participantes também são consumidores dos serviços turísticos das localidades que visitam para participar de um evento, podendo até realizar atividades paralelas àquela que motivou sua viagem.

Diante desse contexto, são pertinentes os estudos acadêmicos que buscam explicar a dinâmica existente entre a realização de festivais culturais e folclóricos e o desenvolvimento local e turístico das localidades sedes. Dessa forma, o presente artigo tem como objetivo analisar os festivais culturais, que são grandes eventos, como estratégia de desenvolvimento local dos destinos turísticos,evidenciando o cenário brasileiro da realização de grandes eventos, identificando de que forma as destinações podem utilizar esses eventos como estratégias de desenvolvimento local e do 
turismo, e por fim analisando os impactos socioeconômicos gerados a partir da realização de eventos nos destinos sedes.

Quanto aos desdobramentos metodológicos, a pesquisa se caracteriza como exploratória, uma vez que busca e mostra de que forma os eventos culturais podem contribuir para o desenvolvimento do turismo nos destinos sedes, fazendo inicialmente um debate teórico a respeito do assunto. Utilizou-se inicialmente abordagem teórica do tema, sendo o estudo construído a partir de pesquisas em periódicos nacionais e internacionais, assim como relatórios de pesquisa sobre o tema. Como subsídio para apresentação de dados sobre os eventos culturais no Brasil, foi feita uma análise de documentos que mostram a dinâmica dos grandes eventos no país, respaldando os resultados apresentados no trabalho. Nesse contexto, é apresentado o caso do Festival Folclórico de Parintins (AM) destacando o impacto dessa festa no desenvolvimento do município amazonense.

O presente trabalho se justifica com base nessas inquietações, uma vez que a academia tem papel importante na problemática e solução de questões deste tipo, fazendo um diagnóstico do ambiente estudado e posteriormente propondo soluções para possíveis problemas. $\mathrm{O}$ trabalho tem como questão problema: de que forma os eventos culturais e festivais podem contribuir para o desenvolvimento dos destinos turísticos?

O desenvolvimento local sustentável de um destino turístico acontece quando se promove de forma igualitária benefícios sociais, ambientais e econômicos para a comunidade receptora, contribuindo para a coexistência das atividades cotidianas dos residentes e a visitação dos turistas, havendo um consumo consciente do espaço e dos elementos que o compõe por partes dos visitantes, respeitando a cultura endógena, gerando reciprocidades entre os principais agentes da atividade turística, o residente e o visitante. Dessa forma, os festivais podem vir a contribuir para concretização do desenvolvimento dos destinos, e estudos como esse são necessários uma vez que o debate sobre os efeitos do turismo e a existência de indicativos que comprovem a efetiva contribuição desses eventos para o desenvolvimento das destinações turísticas são temas recorrentes nas pesquisas e planejamento do setor.

\section{Desenvolvimento, turismo e eventos culturais: uma abordagem teórico- histórica}

O turismo é visto como atividade econômica com vasta potencialidade geradora de efeitos na maioria das vezes observados como "positivos". Esse papel é geralmente reforçado por planos e programas de governos na maior parte dos países que optam pelo turismo e incentivam o desenvolvimento da atividade para fomentar a geração de empregos e renda e a entrada de divisas. Essa questão diz respeito à possibilidade do turismo desenvolver as comunidades receptoras e os locais que investem na sua organização e planejamento. Dessa forma, o turismo contribuiria para fomentar aspectos do desenvolvimento, e principalmente do chamado desenvolvimento local endógeno.

Constituir meios pelos quais as sociedades possam se organizar de forma igualitária entre as classes configura-se como uma necessidade no 
contexto da globalização. O processo de desenvolvimento de um país ou região deve ser pautado e planejado nesse sentido, pois só assim os efeitos necessários e desejados pela população ali existente poderão ser alcançados.

Diante das ideias que caracterizaram principalmente o final do século XX e pautaram o debate sobre desenvolvimento e dos problemas causados pelo uso indiscriminado de recursos naturais, percebe-se a necessidade de buscar cada vez mais meios que possibilitem o desenvolvimento da sociedade de forma global, respeitando os princípios da sustentabilidade, uma vez que se vive atualmente um período de alto índice de consumo de recursos que irão fazer falta futuramente, existindo ainda a preocupação com os indivíduos que compõem essa sociedade, dando-lhes os meios necessários para a sua reprodução.

Sachs (1993) produziu reflexos sobre os modelos tradicionais de desenvolvimento e apresentou dimensões do que chama "ecodesenvolvimento", para ele o desenvolvimento ocorre quando há uma sintonia com os princípios da sustentabilidade. $O$ autor apresenta a sustentabilidade na sua dimensão social, na qual o principal anseio é possibilitar o acesso de toda população às melhorias sociais, de forma que não exista nenhum tipo de exclusão, independentemente de classe social; na dimensão econômica, o processo de gerenciamento e gestão dos recursos financeiros mundiais deve ter maior atenção, "a eficiência econômica deve ser avaliada mais em termos macrossociais do que apenas por meio de critérios de lucratividade microempresarial' (SACHS, 1993, p. 25).

Dentro dessa abordagem, a sustentabilidade ecológica para Sachs (1993) diz respeito aos fatores que possibilitam a interação com a natureza, utilizando seus recursos de forma renovável. A sustentabilidade espacial surge o equilíbrio entre a ocupação dos espaços urbanos e rurais, buscando melhorar a distribuição territorial dos conglomerados humanos. As ideias de Sachs (1993) tem consonância com os debates sobre o desenvolvimento sustentável, expressos principalmente no Relatório Brundtland, publicado em 1987, e até hoje influenciando as proposições da relação entre desenvolvimento, ambiente e políticas públicas.

Todas as dimensões debatidas por Sachs (1993) são fundamentais no processo de fortalecimento do desenvolvimento local, de forma que os agentes construtores da sociedade devem estar em sintonia com os meios nos quais estão inseridos, sendo a comunidade o agente principal dessa dinâmica, pois suas características culturais, sociais, seus pensamentos políticos são os elementos necessários e primordiais na construção do planejamento da comunidade, para Fortunatu e Neffa (2014, P. 61):

[...] o fazer local pode ser considerado como uma estratégia voltada para o desenvolvimento endógeno, visto que auxilia o crescimento econômico de determinada região, por agregar valor à produção local movimentando sua economia e incorporando aspectos políticos, socioculturais e tecnológicos). 
Dessa forma, o desenvolvimento local tem em suas origens a concepção de que a comunidade pode se promover caso haja uma união entre todos em busca de um bem comum (MARTINS, 2002). Dentro dessa discussão, se pode inserir o turismo enquanto atividade promotora do desenvolvimento local e de igualdades sociais entre os indivíduos, haja vista que seu caráter econômico gerador de emprego e renda se destaca dentre as demais características.

No entanto, necessita-se de atenção para os desdobramentos de sua execução, pois é preciso atentar-se para pontos importantes como a participação social na atividade, e os seus impactos no meio ambiente natural e cultural da localidade receptora, uma vez que a chegada de indivíduos alheios às lógicas locais dos destinos onde irão permanecer por um curto espaço de tempo pode alterar a dinâmica social do lugar gerando efeitos positivos ou negativos.

A partir da descoberta de um lugar como destino do turismo, a comunidade lida com as realidades referentes a uma nova dinâmica inserida na sua localidade, e busca meios pelos quais o turismo se alie às possibilidades e alternativas de melhoria de sua própria reprodução social, tentando multiplicar benefícios.

Uma vez que o turismo adquiriu o status de atividade promotora de desenvolvimento econômico e social, o aumento do número de investimentos na atividade turística começa a modificar e maximizar benefícios nas localidades receptoras, de forma que todos aqueles envolvidos direta ou indiretamente são atendidos de alguma forma pelas benfeitorias proporcionadas pelo turismo, e são vários os fatores que levam à efetivação positiva da atividade, mas nem sempre é possível garantir que o turismo possa gerar apenas impactos positivos (TOMAZZONI, 2009).

Nesse cenário, a participação da comunidade na tomada de decisões é relevante, pois na medida em que a atividade turística adentra a uma localidade, os seus residentes devem ser os principais beneficiários (TOMAZZONI, 2009), o que na maioria das vezes não chega a acontecer, pois a regulação da atividade turística por parte do estado tende a beneficiar os agentes de mercado, já que são eles os geradores de receitas para os municípios.

No Brasil, o turismo tem se configurado como uma importante atividade econômica e social. Tendo em vista que o país possui diversas formações naturais e manifestações culturais que despertam interesse para visitá-lo, o turismo se utiliza mercadologicamente dessas características, gerando algumas vezes efeitos que podem ir ao encontro dos objetivos das comunidades, e outras vezes gerando efeitos questionáveis do ponto de vista do desenvolvimento local.

Porém, desenvolver a atividade turística não implica dizer que é apenas necessário ter elementos atrativos aos olhos dos visitantes, precisase de política pública que garanta o desenvolvimento da atividade turística e dos municípios receptores de forma sustentável, haja vista que com o entendimento do turismo como atividade de caráter relevante economicamente, inicia-se um ciclo de ações para garantir tais vantagens aos destinos, sendo necessária a criação e implantação de diretrizes 
específicas para a atividade, de forma que haja uma regulação com vistas a proporcionar melhores condições aos indivíduos direta ou indiretamente ligados a ela (AZEVEDO; FIGUEIREDO; NÓBREGA; MARANHÃO, 2013).

O turismo apesar de poder gerar em alguns casos problemas para os destinos turísticos vem mostrado que é elemento multiplicador de riquezas. Segundo o MTUR (2013), a atividade tem se destacado com participação de $3,7 \%$ no produto interno bruto, tendo entre os anos de 2003 e 2009 uma taxa de crescimento $(32,4 \%)$ maior do que a taxa de crescimento da economia do país $(24,6 \%)$. Todavia desenvolver o turismo não pode ser apenas geração de receitas, é promover uma atividade que atende aos anseios de todos os envolvidos, inclusive a comunidade receptora de forma geral, promovendo políticas que envolvam os residentes nos debates e decisões inerentes à gestão dos destinos turísticos.

Azevedo et. al. (2013, p. 20) expressam a realidade existente no país no que diz respeito à participação popular na tomada de decisões em projetos de interesse comum: "No território nacional brasileiro são poucas as experiências bem sucedidas quanto à participação comunitária em diferentes projetos, inclusive nos turísticos". Nesse sentido, há um atraso na política de desenvolvimento do turismo no Brasil, pelo menos na prática, uma vez que a participação da sociedade se destaca como essencial no planejamento dos destinos, pois são os residentes aqueles que vivenciam diariamente a realidade das regiões turísticas, podendo eles conceber apontamentos minuciosos a respeito das fragilidades e potencialidades das localidades exploradas pelo turismo.

Mesmo com suas fragilidades, o Brasil tem buscado meios pelos quais pretende promover o desenvolvimento do turismo em toda sua extensão, prova disso é que com a criação do MTUR em 2003, programas e planos vem sendo implantados com 0 intuito de atender os anseios dos diversos atores do cenário turístico nacional. Dentre essas ações tem-se a elaboração do PNT e do Programa de Regionalização do Turismo (PRT). No entanto, o país ainda necessita de outras ações que tenham uma eficácia mais evidente e priorize o turismo como uma atividade de promoção de bem estar social, não apenas como ferramenta de geração de renda.

Os eventos culturais e festivais, como já foi assinalado, têm papel importante nesse processo. A criação de acontecimentos variados faz parte da dinâmica de muitas sociedades e culturas. As celebrações religiosas, festas cívicas, encontros culturais e esportivos e até mesmo reuniões dos mais variados tipos são encontrados em muitas configurações de sociedades e culturas na história. A antiguidade clássica produziu diversos acontecimentos e celebrações, e as estruturas logísticas de facilitação dessas realizações tiveram que ser criadas de igual modo. Esses acontecimentos marcados no tempo e no espaço são características do conceito atual de evento, no entanto eles se realizam de forma diversa.

O grande marco para o conceito moderno de evento aconteceu após a Revolução Industrial, período caracterizado por grandes mudanças na sociedade, que refletiram nos tipos de eventos realizados, e quando surgiram os eventos científicos e técnicos, a reboque do próprio desenvolvimento do capitalismo e do desenvolvimento da ciência como 
forma de conhecimento mais adaptado ao modo de produção em processo de solidificação.

No século XIX, em 1841, acontece o Congresso Antialcoólico nas cidades de Leicester e Loughborough, para o qual o inglês Thomas Cook organiza a ida de 570 pessoas para participarem do congresso. Este período é considerado de fato o surgimento do turismo e do conceito moderno de evento. No entanto, o turismo de eventos como segmento se consolidou como atividade econômica e social principalmente no século XX, quando recebeu contribuições dos mais diversos eventos, como os eventos esportivos, feiras e exposições universais. Os avanços tecnológicos, após o surgimento do automóvel seguido do avião, encurtaram as distâncias e ofereceram rapidez, segurança e conforto às viagens turísticas, esses avanços tornaram-se a mola propulsora para o desenvolvimento do turismo e, por conseguinte para o turismo de eventos (MATIAS, 2010).

Até meados do século $X X$, não se tinha nenhuma experiência na organização de eventos, essa realidade foi modificando e tomou impulso após a $2^{\circ}$ Guerra Mundial na década de $1950 \mathrm{com}$ o surgimento das organizações de classes profissionais e com o desenvolvimento industrial.

Os eventos podem ser dos mais diversos tipos e essas categorias incluem, conforme explica Getz (2000), celebrações culturais (como festivais, carnavais, paradas, festas religiosas), artísticas e de entretenimento (concerto e outras performances, exibições, cerimônias de premiação), de negócios e comerciais (feiras, exposições, convenções, reuniões e conferências), de competições esportivas (profissionais e amadoras), educacionais e científicas (seminários e workshops, congressos e conferências), políticas e comemorativas do Estado (inaugurações, investiduras, visitas de personalidades importantes), recreacionais (esporte ou jogos para diversão), e eventos privados (casamentos e festas sociais).

Em estudo recente, Matias (2010, p.107) afirma que em relação ao número de participantes os eventos podem ser classificados em: Pequeno até 150 participantes; Médio - entre 150 e 500 participantes; Grande acima de 500 participantes; Megaevento - acima de 5.000 mil participantes. Dessa forma, os megaeventos, por exemplo, caracterizam-se conforme Matias (2010) como evento de lazer e turismo em larga escala, como os Jogos Olímpicos ou as Feiras Mundiais. Geralmente é de curta duração, com consequências de longa duração para as cidades que os sediam. Está associado à criação de infraestrutura e comodidades para o evento, frequentemente tendo débitos em longo prazo e sempre requerendo programação com bastante antecedência. Um megaevento, se bem sucedido, projeta nova (ou talvez renovada) e persistente imagem positiva da cidade-hóspede por meio da mídia nacional e internacional, particularmente por cobertura de televisão.

Dentro de uma perspectiva conceitual, se percebe que o Festival Folclórico de Parintins/AM não se caracteriza como um megaevento, mas sim como um grande evento cultural. Esse tipo de evento contribui para o reforço identitário de um povo, tem suas origens nas festas, são coletivos e públicos, acontecem em espaços públicos ou semi-públicos e arregimentam um grande número de pessoas que se caracterizam por se envolverem nas 
programações planejadas como brincantes, participantes ou públicos assistentes.

Nesse contexto, os benefícios gerados pelos eventos culturais para o turismo nas cidades proporcionam à comunidade envolvida nesses acontecimentos uma maior possibilidade de obter efetivamente os frutos positivos gerados pelo setor. Percebe-se também que o estado e o mercado propagam os benefícios dos megaeventos no desenvolvimento das localidades principalmente em aspectos econômicos e culturais, porém na maioria das vezes não há uma consulta aos moradores das cidades sedes para saber se o evento é de interesse deles, pois muitas vezes não participam efetivamente do seu planejamento, nem da sua execução.

\title{
Eventos culturais e festivais como estratégias para o desenvolvimento e destinos turísticos
}

Os grandes eventos esportivos e culturais estão se destacando cada vez mais como fomentadores do turismo, principalmente na tentativa de melhorar o desempenho da atividade nos períodos de baixa estação, por consequência impulsionam a priori o desenvolvimento local, uma vez que promover um evento implica, no caso do presente estudo, em utilizar os equipamentos e serviços da atividade turística a fim de suprir as necessidades de quem viaja para participar de eventos. Dessa forma podese evidenciar a importância desses festivais para o turismo, na medida em que esse segmento proporciona o fomento da atividade.

Brito e Fontes (2002) fazem sua contribuição, ratificando a importância dos eventos para a atividade turística. Para as autoras:

\begin{abstract}
Qualquer evento que reúna clientela de diferentes localidades cria oportunidade de viagens na medida em que as pessoas se deslocam para participar de um congresso ou exposição, por exemplo, geralmente aproveitando a ocasião para passeios e compras, o que favorece a utilização mais ampla dos bens, atrativos e serviços da cidade (BRITO; FONTES,2002, p. 74).
\end{abstract}

Dessa forma, os eventos culturais, festivais e megaeventos colaboram para a valorização dos espaços, sejam eles turísticos ou não, uma vez que a visitação ao lugar e a interação com a cultura e costumes na maioria das vezes é uma opção para os participantes de eventos nas pausas de suas atividades. O Brasil atualmente tem se destacado e aproveitado alguns eventos como ferramenta de fomento econômico e social, prova disso são os eventos esportivos que aconteceram e irão acontecer no país, a Copa do Mundo de Futebol da Federal Internacional de Futebol (FIFA) em 2014 e os Jogos Olímpicos de 2016 na cidade do Rio de Janeiro. Ambos possibilitaram investimentos em diversas áreas, não só no turismo, assim como projetaram e projetarão o Brasil para o mundo, apesar da controversa idéia de "legados", já que muitas vezes as intervenções urbanas para esses eventos são direcionas apenas a uma parcela da população. 
Mas não são apenas os megaeventos esportivos que vem fomentando a atividade turística, o MTUR destaca que os congressos e eventos técnico-científicos, em nível internacional, são os que vêm promovendo o Brasil enquanto país promissor na área de negócios e eventos. O MTUR (2013), com base em dados da International Congress and Convention Association (ICCA) divulgados no ano de 2011, afirma que o país tem se firmado como importante destino de eventos internacionais, ocupando a sétima posição no ranking da ICCA.

No ano de 2003 havia no Brasil 22 cidades que realizavam eventos internacionais, já no ano de 2008 esse número passou para 45 cidades (ICCA apud MTUR, 2010), dessa forma percebe-se que os eventos no Brasil não são práticas que entraram em evidência apenas com a realização dos megaeventos de 2014 e 2016. Há um constante crescimento na realização de eventos no país dos mais variados tipos entre o ano de 2003 e 2008, principalmente os de âmbito internacional, esses números influenciam diretamente nas estatísticas do turismo, já que, como visto nas discussões anteriores, os eventos implicam diretamente na utilização dos equipamentos turísticos e consequentemente na geração de receitas turísticas.

Baseados na prerrogativa de que os eventos movimentam e contribuem para o desenvolvimento do turismo e para o desenvolvimento dos destinos, os dados da Figura 1, confirmam que o Brasil com suas potencialidades vem se destacando no mercado internacional de eventos, fato que também é possível ser confirmado pelas recentes pesquisas do MTUR, mostrando que a atividade turística do país vem se desenvolvendo de forma mais encorpada, além disso, os eventos colaboram para a multiplicação e desenvolvimento da indústria do entretenimento (BRITO; FONTES, 2002).

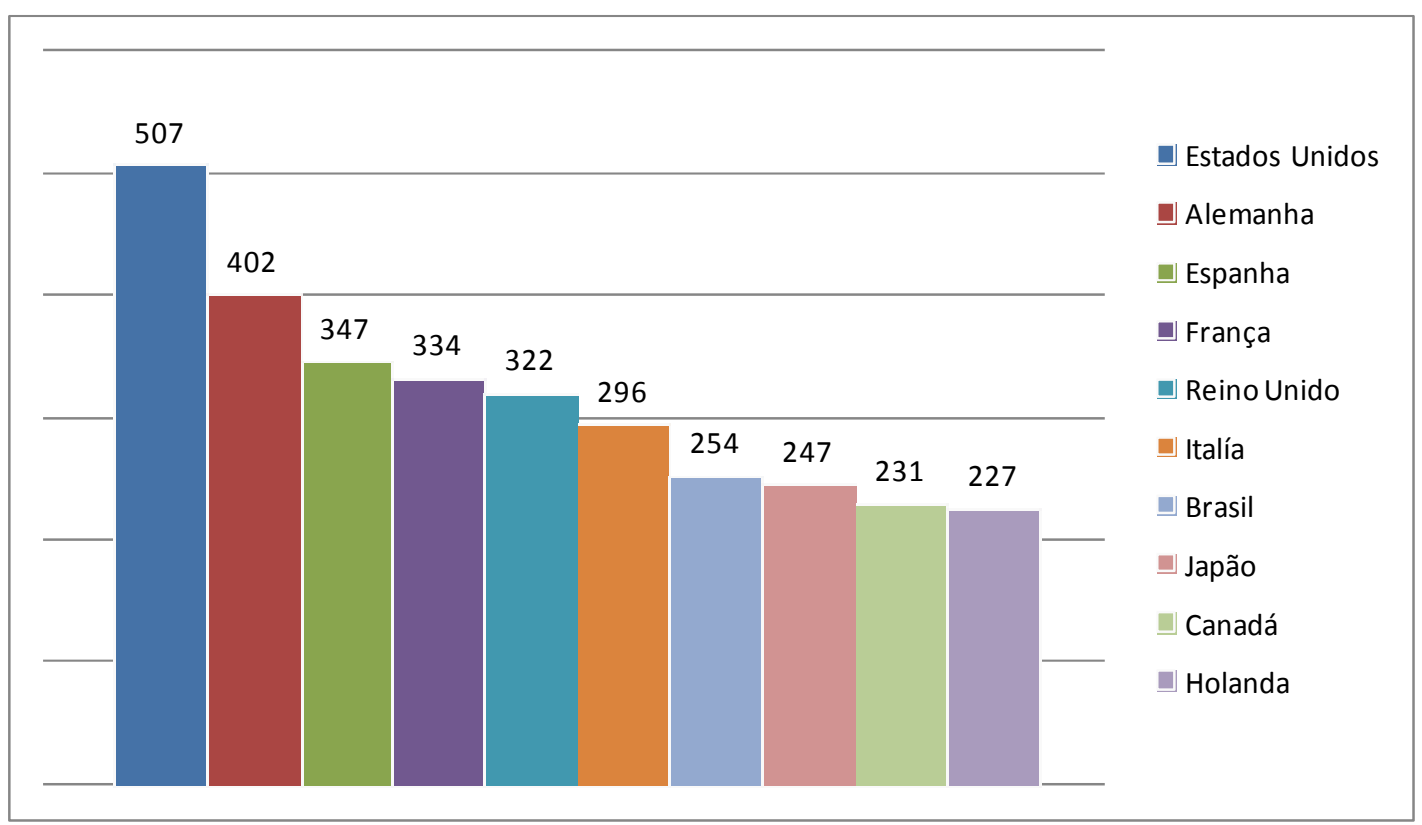

Figura 1: Ranking dos Países, segundo número de eventos (2008).

Fonte: ICCAapudMTUR, 2010.

Figure 1: Ranking of countries according to the number of events (2008).

Source: ICCA apud MTUR, 2010. 
Uma localidade turística deve reconhecer que os eventos são ferramentas de auxilio no fomento à atividade do turismo, independente de qual seja o tipo de evento. Dada a importância do segmento, os eventos foram incluídos pelo governo federal nas políticas de turismo, cujo objetivo é a captação de eventos internacionais como elemento estratégico para diminuir os efeitos da sazonalidade turística (AMORIM, 2003).

Não somente os eventos internacionais, mas qualquer manifestação que se caracterize como impulsionadora do consumo dos elementos que formam o turismo - estrutura e serviços - contribui para diminuir os impactos da sazonalidade. Deve-se existir um fortalecimento da política nacional de turismo no que diz respeito aos eventos, festivais, dentre outras manifestações de cunho cultural e nacional, pois são eles que movimentam - país durante os doze meses do ano, apesar de reconhecer que principalmente os eventos internacionais projetam ainda mais o destino Brasil, e esse número vêm crescendo no país conforme pesquisa divulgada pelo MTUR (ver Figura 2), provando que a política vem surtindo efeitos.

Muito embora esse contexto se demonstre como favorável aos eventos e ao turismo, são necessários estudos mais constantes e profundos para saber de que forma esse eventos estão contribuindo para o turismo brasileiro e para as regiões receptoras, uma vez que se faz pertinente incluir nesse contexto a sociedade de forma geral, e por conseguinte, os efeitos na geração de emprego e renda e a mitigação de problemas socioculturais e ambientais.

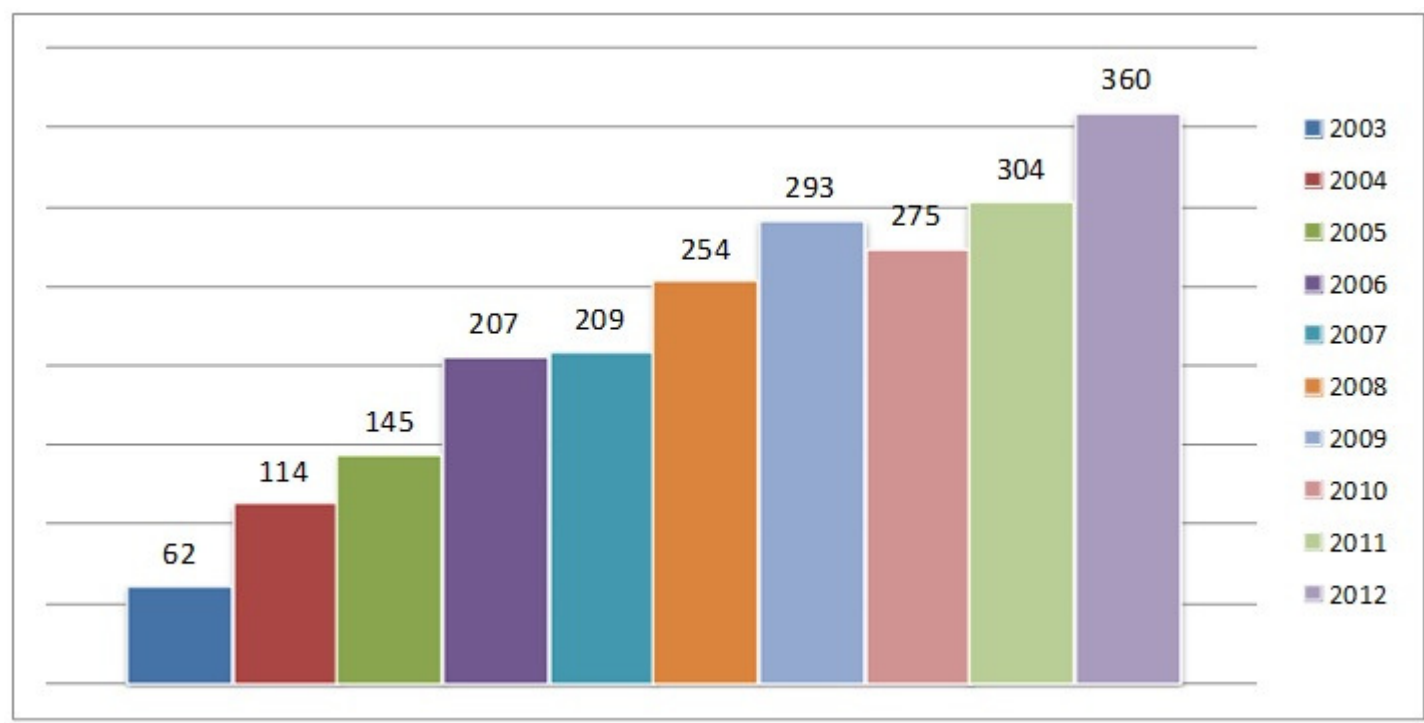

Figura 2: Realização de eventos internacionais no Brasil. Fonte: ICCA apud MTUR, 2010.

Figure 2: Accomplishment international events in Brazil. Source: ICCA apud MTUR, 2010.

Um caminho a ser seguido para que esse processo de inserção da comunidade na atividade turística por meio dos eventos se concretize é fomentar relação entre cultura e eventos, tendo em vista que a cultura se caracteriza como uma das principais atrações dos destinos, e é possível associá-la à realização de eventos que enfatizem os costumes e tradições dos locais, sendo então uma excelente forma de valorizar os indivíduos do lugar e inseri-los no desenvolvimento da atividade turística (FRANCO, et al. 2003). Dessa forma, os eventos culturais podem ser utilizados como mais 
uma ferramenta de desenvolvimento turístico e local, na medida em que o Brasil é detentor de grande potencial cultural e necessita sustentar a infraestrutura de serviços turísticos durante todo o ano.

Os grandes eventos e megaeventos também têm sua importância no âmbito econômico, cultural e social para a destinação turística, mas não se pode pensá-los como uma panacéia para resolver todos os problemas existentes na localidade. Sabe-se que eventos desse tipo não são a única estratégia para resolver questões da sazonalidade, mas pode-se utilizá-los como uma alternativa para aumentar os fluxos sazonais.

Para Britto e Fontes (2002) a sazonalidade é entendida como a concentração das atividades em determinado espaço e tempo e a falta delas em outros períodos, de forma bastante característica, destacando-se a variação do fluxo turístico receptivo e emissivo, variação no volume de chegadas e partidas nos portos, aeroportos, rodoviárias, e a taxa de ocupação das redes hoteleiras.

Esse período sazonal gera grandes consequências nos destinos turísticos, pois a sazonalidade turística observada em baixa estação de qualquer localidade produz, como destaca Britto e Fontes (2002), desemprego específico na área de turismo e áreas afins, mortalidade de micro e pequenas empresas, queda de faturamento de empresas turísticas e afins, alteração no sistema de gestão, alteração na qualidade do atendimento, modificação na política promocional do produto, alteração dos preços em geral, além do incentivo a inflação e a queda do desenvolvimento social. Os destinos se questionam sobre a melhor resolução para sair da sazonalidade turística.

Os eventos culturais de grande porte e os festivais representariam a possibilidade de desenvolvimento local por meio de eventos e turismo. Esse tipo de evento transcende as festas tradicionais, quer sejam religiosas ou cívicas, e baseiam-se no investimento e na atenção na recepção de visitantes e no marketing de cidades. Nesse sentido, os festivais culturais são grandes festas e encontros, em função de um tema ou de uma festa tradicional, que possuem uma organização preocupada não só com as etapas da festa, mas com a recepção do público assistente, e do turista, e que tem como objetivo também a movimentação da comunidade em todos os sentidos, principalmente na geração de efeitos positivos ao desenvolvimento local.

\section{O festival folclórico de Parintins e seus efeitos}

O Festival Folclórico de Parintins é realizado no município de Parintins (AM), na divisa com o Estado do Pará (ver Figura 3).Parintins está situado na llha de Tupinambarana, na margem direita do rio Amazonas, na divisa com o Estado do Pará e foi fundado em 1880, apesar de ser originário de uma aldeia indígena ocupada no século anterior. O município conta atualmente com aproximadamente 110.411 habitantes, em área territorial total de $5.952,390 \mathrm{~km}^{2}$.

A maior parte dos habitantes continua a sobreviver de atividades tradicionais como o extrativismo e a pesca, e mais recentemente a pecuária 
também se configura como atividade importante para a população do município, apesar dos conflitos gerados pela derrubada da mata para criação de gado. A produção agrícola ainda é de subsistência e o abastecimento sofre principalmente nos períodos do festival. Com a crescente urbanização da cidade, principalmente em função do aumento dos fluxos turísticos derivados do festival, as atividades de comércio e de serviços vêm ganhando espaço na economia local. Nesse quadro, o município apresenta um IDH de 0,658 com PIB de $\mathrm{R} \$ 675.333$ mil e PIB per capita de $\mathrm{R} \$ 6.504,35$ (SOUZA, 2013).

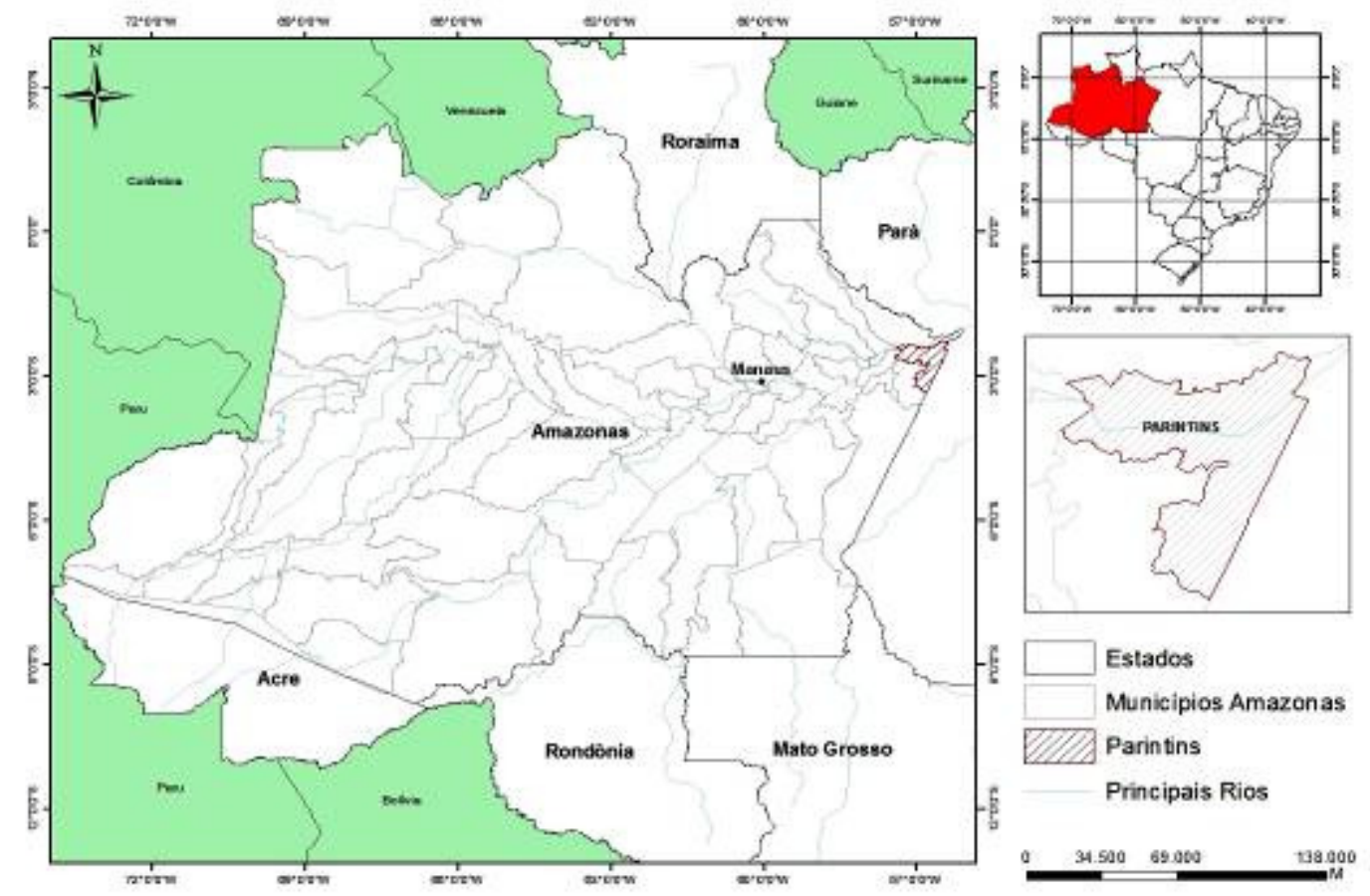

Figura 3: Ilustração da localização de Parintins (AM). Fonte: LAENA - NAEA (2015). Figure 3: Illustration of the location of Parintins (AM). Source: LAENA - NAEA (2015).

O festival tem origem na festa do Bumba-meu-boi e Boi-Bumbá, opereta popular que ocorre em vários estados brasileiros, síntese de cultura africana, indígena e européia. Geralmente segue em dramatização recitada e cantada na qual a personagem Catirina grávida tem desejo de comer a língua de um boi, que é morto e depois ressuscitado. Os dramas são apresentados em locais públicos ou em cortejos também, associados ao ciclo das festas juninas, mês de junho (FIGUEIREDO; TAVARES, 2006).

No Amazonas incorporou ainda mais personagens indígenas (como a Cunhã Poranga e as tribos) e se transformou em espetáculo e também evento de grandes proporções. Os bois amazonenses são mais antigos, mas o Festival teve sua primeira edição em 1965. Na grande arena do Bumbódromo os bois Garantido (vermelho) e Caprichoso (azul) procuram superar um ao outro em três dias de festival, realizado a partir de 2008 sempre no último fim de semana do mês de junho. Protagonizam por meio da competição da dança, da música e da encenação dramática histórias pontuadas por ritmos eletrizantes, figurinos requintados, sofisticadas 
alegorias, que refletem as características da região, interpretam a Amazônia do índio e do caboclo, contando as lendas, mitos, hábitos e rituais.

A rivalidade dos bois torna o Festival mais curioso, pois influencia na geografia do lugar. A cidade é dividida em duas partes: Garantido - na cidade baixa do Garantido, rio acima no bairro de São José, onde as residências e ruas são enfeitadas da cor vermelha; e Caprichoso - próximo ao Centro e nos bairros, rio abaixo, ruas e residências decoradas da cor azul, rivalidade que interfere na visualidade da cidade e no modo de viver e ver de seus habitantes.

Segundo Valentim (2005) os bois celebravam os santos juninos, saíam às ruas da cidade, onde encontros eram inevitáveis e muitas vezes, violentos. A brincadeira, no entanto, foi se organizando e com o passar dos anos evoluiu para o grande espetáculo que é hoje. $O$ evento valoriza os artistas da localidade, aperfeiçoando os recursos humanos locais por meio do intercâmbio com outros artistas e, também promovem a mão de obra local: artistas plásticos, costureiros, figurinistas, cenógrafos, iluminadores, cenotécnicos, maquinistas, maquiadores, entre outros (Figura 4).
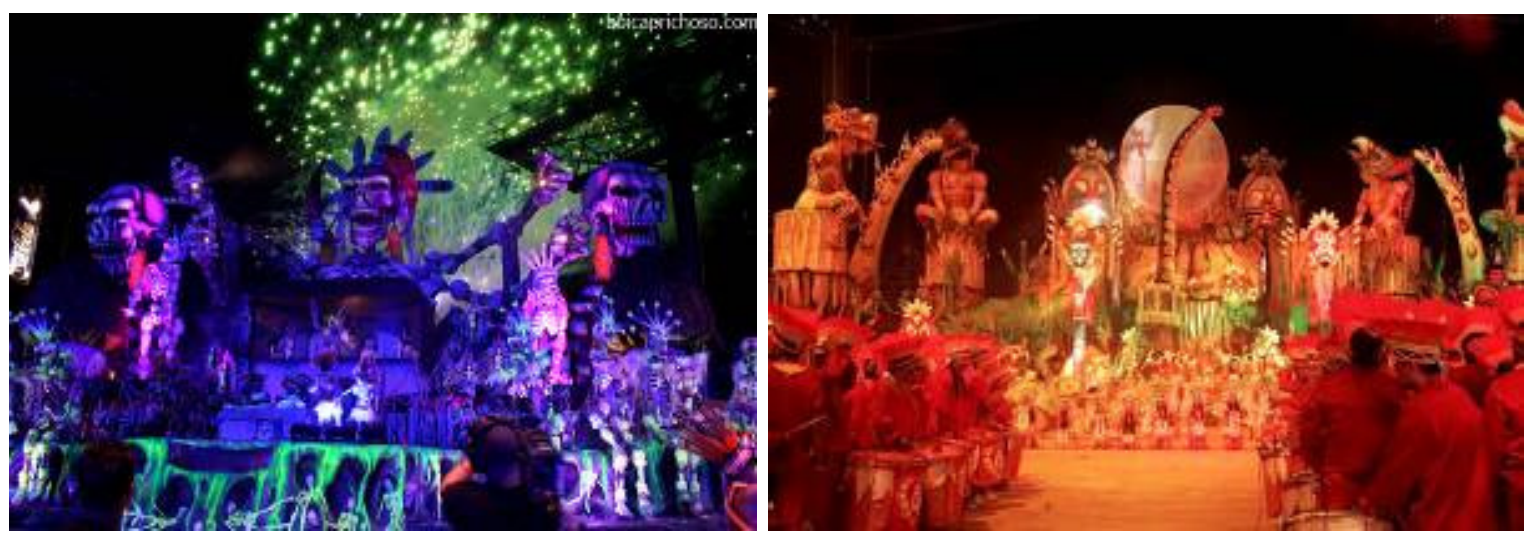

Figura 4: Apresentação dos Bois Caprichoso (a esquerda) e Garantido (a direita)

Fonte: Portal dos Bois Caprichoso e Garantido

Figure 4: Presentation of Bois Caprichoso (left) and Garantido (right)

Source: Portal of Bois Garantido and Caprichoso

O Festival Folclórico de Parintins tornou-se um grande evento ao longo dos anos, e a festa se transformou então na principal atividade econômica do município gerando divisas e diversos impactos socioeconômicos. Um dos grandes problemas durante o festival é a recepção de uma grande massa de visitantes e turistas, e a população local, que segundo o IBGE (2014) é de 110.411, dobra no período do festival, com isso surgem questões que comprometem a qualidade da estada do turista, hotéis lotados, preços elevados, entre outros e principalmente, prejudicam os habitantes e a qualidade de vida mesmo que seja por um curto período de tempo.

Por outro lado, esses efeitos vêm sendo alvo de direcionamentos específicos do planejamento urbano e turístico, para que sejam diminuídos e, dessa forma, garantir que os efeitos positivos aumentem. O festival é de grande relevância para o Estado do Amazonas, que muitas vezes sofre com 
o efeito da sazonalidade no que diz respeito à atividade turística. O evento está consolidado e oficialmente irá para a 50 edição no ano de 2015 , tem caráter regional, atraindo até turistas nacionais, e pessoas de outros países - em número bem pequeno - também têm participado do Festival.

A Empresa Estadual de Turismo (Amazonastur) é um órgão oficial que tem como objetivo a promoção do turismo e, portanto, a promoção do festival com a finalidade de divulgar a marca "Amazonas" no mercado turístico internacional e nacional. O Órgão tem a missão de "fomentar o turismo de forma sustentável em consonância com a política Estadual de Turismo", dessa forma, o evento é divulgado em todas as ações das quais participam a Amazonastur, como Feiras, Congressos, Seminários e Eventos nacionais e internacionais, em países como Portugal, Espanha, Alemanha, Itália, Estados Unidos, Japão, China, dentre outros. É divulgado ainda em ações nacionais e internacionais com a realização de workshops e roadshows promovidos pelo Governo do Amazonas, pelas embaixadas do Brasil no exterior e pela EMBRATUR no exterior e pelo Ministério do Turismo no Brasil (informações verbais do Chefe do Departamento de Promoção e Marketing Turístico).

Nesta ação promocional do festival, os investimentos por parte da Amazonastur nos últimos cinco anos tem sido em torno de $R \$ 2,5$ milhões, sendo aproximadamente $R \$ 200$ mil gastos por ano em material promocional.

A divulgação é feita também em blogs, sites, programas de turismo em canais abertos e fechados de TV, revistas e jornais de turismo, revistas de bordo de companhias aéreas, e guias bilíngues, todos no âmbito nacional e internacional. Outras ferramentas são utilizadas na divulgação e promoção do festival, como a realização de Familiarization Tours (Famtours), com a presença de grupos de operadores, agentes de viagens e formadores de opinião, a realização de Presstrips, com a presença de grupos de jornalistas dos mais variados veículos de comunicação, também no âmbito nacional e internacional. Todas as ações da Amazonastur possuem apoio do trade turístico local, hotelaria de selva e urbana, operadores e agentes do receptivo local, restaurantes, entre outros, além da EMBRATUR e Ministério do Turismo.

Conforme dados da Secretaria de Estado de Cultura do Amazonas, o evento é organizado pelos órgãos públicos da esfera municipal, estadual e federal, no qual trabalham aproximadamente 1.734 servidores públicos dos sistemas de segurança pública, saúde, cultura, infraestrutura, turismo e demais setores (SEC, 2014).

O local de realização do espetáculo, o Bumbódromo, foi inaugurado em 1988. Projetado especialmente para acomodar a apresentação dos bois, hoje tem capacidade de acomodar mais de 17,5 mil pessoas e passou por uma obra de recuperação e ampliação sendo reinaugurado no ano de 2013, totalmente modernizado. 

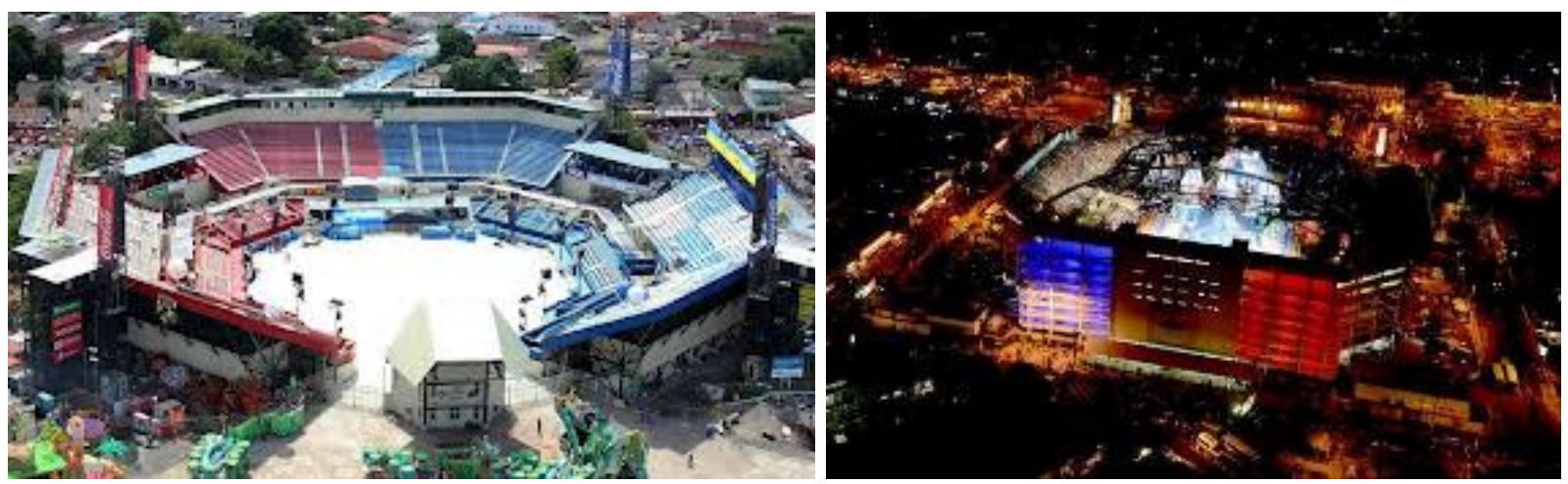

Figura 5: Bumbodromo em Parintins, antes (a esquerda) e depois da reforma (a direita).

Fonte: Portal do Amazonas

Figure 5: Bumbodromo in Parintins, before (left) and after the reform (right).

Source: Portal of the Amazonas

Em sua $48^{\circ}$ edição no ano de 2013, o Festival Folclórico de Parintins teve seu grande espetáculo artístico na comemoração do centenário dos bois-bumbás Garantido e Caprichoso que neste ano se tornaram Patrimônio Cultural do Amazonas, conforme o decreto no 33.684, de 26 de junho de 2013. O decreto é um reconhecimento histórico da importância dos boisbumbás para a cultura e a economia regional. Nesse ano, participaram aproximadamente 3.000 brincantes de cada associação folclórica.

Tamanha é a relevância do Festival que os investimentos realizados para operacionalização do evento ao longo dos últimos quatro anos vêm aumentando, segundo dados da Secretaria de Estado de Cultura (SEC) e conforme pode ser visto na Tabela 1.

Tabela 1: Investimento do Governo Estadual e Federal na operacionalização do evento nos últimos quatro anos.

Table 1: Investment of the State and Federal Government in operation alizing the event the past four years.

\begin{tabular}{|c|c|c|c|c|}
\hline \multicolumn{5}{|c|}{ INVESTIMENTOS } \\
\hline ITEM & \multicolumn{4}{|c|}{ ANO } \\
\hline $\begin{array}{c}\text { Apoio Financeiro } \\
\text { do Governo }\end{array}$ & $\mathbf{2 0 1 1}$ & $\mathbf{2 0 1 2}$ & $\mathbf{2 0 1 3}$ & $\mathbf{2 0 1 4}$ \\
\hline Total & $10.780 .000,00$ & $15.031 .506,65$ & $18.898 .838,38$ & $16.944 .909,96$ \\
\hline \multicolumn{4}{|c|}{$\mathbf{6 1 . 6 5 5 . 2 5 4 , 9 9}$} \\
\hline
\end{tabular}

Fonte: Secretaria de Estado da Cultura (2014).

Source: Secretariat of State for Culture (2014).

Segundo funcionário da $\mathrm{SEC}^{2}$, as verbas públicas são repassadas por meio de convênios e o total de investimentos provém da verba do governo do estado, governo federal e das empresas privadas que patrocinam 0 evento.

Dentre os patrocinadores destaca-se a empresa Coca-Cola Brasil como patrocinador Master, patrocinando o evento há 20 anos. A empresa investiu no ano de $2013 \mathrm{R} \$ 6,5$ milhões, sendo $R \$ 2,5$ milhões diretamente no patrocínio aos bois Garantido e Caprichoso (COCA-COLA BRASIL, 2013). Os investimentos no festival ao longo desses 20 anos ultrapassam os $\mathrm{R} \$ 76$ milhões de reais, tornando-a a maior patrocinadora do evento. 
Segundo declarações do vice-presidente de Comunicação e Sustentabilidade da Coca-Cola Brasil no site da empresa, Marco Simões, o patrocínio ao Festival de Parintins é um dos mais relevantes patrocínios culturais que fazem no país, fruto de um relacionamento próximo e duradouro com o Amazonas e seus habitantes.

A visibilidade do festival é tão grande para os patrocinadores que algumas empresas como Bradesco, Skol e Coca-cola mudam a cor das suas marcas e de seus produtos para serem comercializados no período do evento, além da exposição de suas peças promocionais no Bumbódromo.

Parintins apresenta durante o festival a injeção de 50 milhões de reais na economia local, movimentando as atividades econômicas do município, porém não há dados oficiais do município que detalhem toda essa movimentação por segmento (SEC, 2013). No ano de 2014, a principal empresa fornecedora do evento, Tucunaré Turismo, contou com uma mão de obra de aproximadamente 720 pessoas contratadas como prestadoras de serviços distribuídas em atividades de segurança, limpeza, indicadores, e entre outros. Em audiência pública realizada na Câmara Municipal no mês de abril de 2014, na qual os representantes do governo estadual e municipal, o trade, os órgãos envolvidos e fornecedores estavam presentes, a proprietária da Tucunaré Turismo indicou que 98\% dessa mão de obra contrata são da cidade de Parintins.

A população apesar de sentir os problemas da realização do evento, com engarrafamentos, serviços públicos limitados e outras situações típicas de grandes aglomerações, percebe os "benefícios" e apontam as principais razões do apoio ao Festival, além das questões exclusivamente culturais e simbólicas. A Amazonastur identificou essa percepção em pesquisa socioeconômica junto aos moradores de Parintins (Tabela 2):

Tabela 2: Benefícios do Turismo para o município, segundo a População.

Table 2: Benefits of Tourism for the municipality, according to the Population.

\begin{tabular}{|c|c|c|c|c|c|}
\hline \multicolumn{6}{|c|}{ BENEFICIOS DO TURISMO PARA O MUNICÍPIO } \\
\hline \multirow[b]{2}{*}{ BENEFÍCIOS DO TURISMO } & \multicolumn{5}{|c|}{$\begin{array}{ll}\text { ANO } \\
\end{array}$} \\
\hline & $\begin{array}{l}2010 \\
(\%)\end{array}$ & $\begin{array}{c}2011 \\
(\%)\end{array}$ & $\begin{array}{c}2012 \\
(\%)\end{array}$ & $\begin{array}{c}2013 \\
(\%)\end{array}$ & $\begin{array}{c}2014 \\
(\%)\end{array}$ \\
\hline $\begin{array}{c}\text { A cidade recebeu maior } \\
\text { urbanização }\end{array}$ & 27,23 & 23,57 & 22,17 & 25,15 & 25,88 \\
\hline Maior geração de empregos & 13,66 & 18,05 & 15,33 & 17,23 & 17,21 \\
\hline Maior distribuição de renda & 12,50 & 10,87 & 10,99 & 9,73 & 8,95 \\
\hline Outros & 46,16 & 46,60 & 50,15 & 46,99 & 47,03 \\
\hline Não citou & 1,36 & 0,91 & 0,45 & 0,89 & 0,93 \\
\hline
\end{tabular}

Fonte: Empresa Estadual de Turismo - Amazonastur - Pesquisa Socioeconômica Festival Folclórico de Parintins 2010-2014.

Source: State Tourism Company - Amazonastur - Socioeconomic Research Parintins Folklore Festival 2010-2014.

Observa-se os benefícios do turismo para o município citado na Tabela 2 pela população, na qual 25,88\% afirmaram que o principal benefício foi a maior urbanização que a cidade recebeu; 17,21\% apontaram a maior geração de empregos; e 8,95\% citam a maior distribuição de renda. 
Nota-se que no ano de 2010 a população percebeu uma maior urbanização com $27,23 \%$ em relação aos próximos anos de festival. Já no que se refere a "maior geração de empregos" foi percebido no ano de 2011 com 18,05\% maior que nos demais anos, em grande medida essa dinâmica ocorre devido aos fluxos de visitantes e investimentos que ocorrem a cada ano. Em 2012 o bumbódromo passou por uma grande reforma e foi modernizado. Ao todo foram investidos cerca de 40 milhões de reais na obra de infraestrutura, 0 que pode a, logo prazo melhorar os indicadores do festival (SEC, 2013).

Pelos dados apresentados, somente em 2013 foram investidos no Festival Folclórico de Parintins mais de 60 milhões de reais, juntando a modernização do Bumbódromo, patrocínio das empresas privadas, a verba recebida do governo para operacionalização e realização do evento. De acordo com dados do órgão oficial do turismo (AMAZONASTUR, 2012) foram identificados os principais emissores de turistas para o Festival Folclórico.

Tabela 3: Distribuição dos Turistas por Procedência.

Table 3: Distribution of TouristsbyOrigin.

\begin{tabular}{|c|c|c|c|c|}
\hline \multicolumn{5}{|c|}{ DISTRIBUIÇÃO DOS TURISTAS POR PROCEDÊNCIA } \\
\hline \multirow[b]{2}{*}{ CIDADES } & \multicolumn{4}{|c|}{ ANO } \\
\hline & $\begin{array}{c}2010 \\
(\%)\end{array}$ & $\begin{array}{c}2011 \\
(\%)\end{array}$ & $\begin{array}{c}2012 \\
\text { (\%) }\end{array}$ & $\begin{array}{c}2013 \\
(\%)\end{array}$ \\
\hline Manaus & 58,24 & 52,17 & 47,81 & - \\
\hline Santarém & 4,12 & 3,96 & 7,02 & - \\
\hline São Paulo & 2,35 & 3,95 & 4,39 & - \\
\hline Belém & 4,12 & 3,95 & 5,70 & - \\
\hline Itacoatiara & 5,29 & 2,77 & 2,19 & - \\
\hline Outros & 25,88 & 33,20 & 32,89 & - \\
\hline \multirow[b]{2}{*}{ ESTADOS } & \multicolumn{4}{|c|}{ ANO } \\
\hline & $\begin{array}{c}2010 \\
(\%)\end{array}$ & $\begin{array}{c}2011 \\
(\%)\end{array}$ & $\begin{array}{c}2012 \\
(\%)\end{array}$ & $\begin{array}{c}2013 \\
(\%)\end{array}$ \\
\hline Amazonas & 67,06 & 61,26 & 62,28 & - \\
\hline Pará & 15,88 & 15,02 & 15,79 & - \\
\hline São Paulo & 3,53 & 5,14 & 4,39 & - \\
\hline \multirow[b]{2}{*}{ PAÍSES } & \multicolumn{4}{|c|}{ ANO } \\
\hline & $\begin{array}{c}2010 \\
(\%)\end{array}$ & $\begin{array}{c}2011 \\
(\%)\end{array}$ & $\begin{array}{c}2012 \\
(\%)\end{array}$ & $\begin{array}{c}2013 \\
(\%)\end{array}$ \\
\hline Brasil & 97,49 & 97,60 & 97,33 & - \\
\hline Estados Unidos & 1,85 & 1,83 & 1,92 & - \\
\hline Europa & 0,66 & 0,57 & 0,75 & - \\
\hline
\end{tabular}

Fonte: Empresa Estadual de Turismo - Amazonastur - Pesquisa Socioeconômica do Festival Folclórico de Parintins 2010-2013.

Source: State Tourism Company - Amazonastur - Socioeconomic Research Parintins Folklore Festival from 2010 to 2013.

Nos últimos anos, permaneceu o predomínio de turistas oriundos de Manaus, que emitiu $47,81 \%$ dos turistas que participaram do Festival em 2012, e é responsável pelo envio de 58,24\% dos turistas no período de 2010 a 2012. Destacam-se também as cidades do Estado do Pará como Belém com $5,70 \%$ emissões de turistas e Santarém, sendo o segundo maior emissor de turistas para o festival com 7,02\% no ano de 2012, seguido da cidade São Paulo como terceiro maior emissor de turistas em 2012. Quanto 
aos países emissores, o volume de turistas do exterior correspondeu a $2,67 \%$ do total, sendo 1,92\% de turistas provindos dos Estados Unidos e 0,75\% provindos da Europa, principalmente Inglaterra e Alemanha. Já os turistas brasileiros correspondem a $97,33 \%$ do total.

No que se refere aos gastos dos turistas, segundo a Amazonastur (2014) houve um crescimento no gasto médio por dia entre os anos de 2010 e 2014 , saindo de $R \$ 108,24$ para $R \$ 129,75$ por dia, um aumento médio de $\mathrm{R} \$ 21,51$. É importante ressaltar que o custo do ingresso para assistir o espetáculo dos bois varia de $R \$ 500,00$ a $R \$ 900,00$ reais pelos três dias. Os ingressos são vendidos por uma empresa terceirizada. Ingressos de camarotes e áreas vip são ainda mais caros e com flutuações de preço.

Apesar dos grandes investimentos no Festival, o município de Parintins não possui fluxo de turistas fora do período em que o evento é realizado. Entretanto, segundo Oliveira (2011) não é difícil perceber que o Festival possui elementos fundamentais para 0 desenvolvimento da localidade como: a atração de investimentos, promoção do turismo, ações urbanas, e parcerias público-privadas, sendo que o Festival ao longo dos anos apresenta crescimento nos investimentos, infraestrutura, geração de renda e parcerias público-privada através de patrocínios.

A população parintinense se prepara o ano inteiro para a realização deste evento, no planejamento da realização do festival é indiretamente representada nas discussões referentes ao planejamento da realização do festival por vários atores como as associações folclóricas dos Bois Garantido e Caprichoso e associação dos artesãos. Essas discussões são apresentadas durante a realização do Seminário de Revisão Crítica do Festival, realizado pela Secretaria de Estado de Cultura do Amazonas SEC, no período que antecede a realização do evento. O seminário conta ainda com a participação dos órgãos que colaboram com a operacionalização do evento, como corpo de bombeiros, polícia civil, militar e federal, ministério público, juizado de menor, Infraero, secretarias de saúde, cultura, turismo, infraestrutura, departamento de transito, entre outros.

No seminário são discutidas questões referentes ao regulamento do evento, formatação do espetáculo, transmissão do festival, comunicação e marketing, infraestrutura do município, segurança, equipamentos e serviços turísticos, ou seja, todas as questões fundamentais para o funcionamento do município durante a realização da festa.

Nos períodos pré e pós festival, funciona no Bumbódromo as atividades da escola de Artes Liceu de Artes e Ofícios Cláudio Santoro Unidade Parintins, inaugurada em 2013 pelo governo do Estado, através da Secretaria de Estado de Cultura, no qual são ofertados cursos gratuitos para a comunidade de Parintins e dos municípios vizinhos, como Maúes, Barreirinha, Nhamundá. São oferecidos cursos de dança, música, teatro, artes visuais, noções de cinema e outros, atendendo mais de 4 mil pessoas, dentre elas crianças, adolescentes e o público da terceira idade. Para a comunidade parintinense, isso pode representar um dos maiores benefícios gerados pelo festival, pois o Liceu de Artes contemplou no final de 20140 
número de 2.210 alunos e 134 colaboradores, entre instrutores e administrativo, limpeza e conservação, segurança patrimonial e armada.

O Bumbódromo recebe mensalmente 8 mil pessoas para visitação nos espaços culturais, possui biblioteca, sala multimídia, galerias de exposições de artistas plásticos internacionais, nacionais, amazonenses e parintinenses; memoriais do boi garantido e do boi caprichoso, onde ficam as peças usadas pelos brincantes e o cine clube - local onde funciona o único cinema da cidade e tem capacidade para 40 pessoas, com sistema de som digital e projeção em alta definição 3D. Durante a semana é utilizado pelos alunos do curso de audiovisual do Liceu e nos finais de semana e feriados oferece sessões gratuitas e abertas à população.

Antes da existência do Liceu de Artes, o Bumbódromo era um espaço ocioso fora do período do festival, algumas vezes o prédio era depredado pela própria população, roubavam todos os materiais e equipamentos que ficavam no espaço e, atualmente a situação é diferente, pois eles mesmos utilizam o espaço todos os dias. $\mathrm{Na}$ arena, local onde os bois se apresentam, são realizados eventos de pequeno porte como shows, festejos juninos e apresentação de espetáculos do calendário cultural municipal, fora do período do festival.

O Liceu de Artes tem sido elemento fundamental para 0 desenvolvimento do município, foram gerados empregos diretos para população local, pois os professores e corpo administrativo da escola são da própria localidade, e também diminuiu a ociosidade dos próprios alunos dos cursos regulares municipais e estaduais.

\section{Considerações finais}

Buscou-se analisar com esse estudo os eventos como estratégia importante para o desenvolvimento local e turístico dos destinos. A hipótese principal diz respeitos às potencialidades dos eventos culturais em se aliar ao turismo para promover mudanças nos destinos turísticos. A análise do Festival de Parintins demonstrou que os eventos têm possibilidades de proporcionar aos destinos sedes a promoção da atividade turística em virtude da prática desses eventos, tendo em vista que os participantes também são consumidores dos serviços turísticos das localidades as quais os mesmo visitam para participar de um evento, podendo realizar atividades paralelas. Isso ficou demonstrado a partir da ligação indiscutível entre o Festival e a atividade turística, que é sazonal, mas é o ápice do calendário social e da marcação do tempo social no município.

Da mesma forma, foi possível perceber o incremento das relações do Festival e do turismo com as necessidades e transformações da cidade e das áreas rurais do município. Para tanto, foi necessário que a localidade sede desenvolvesse estratégias para se planejar turisticamente, para que, organizada, pudesse desenvolver o funcionamento regular dos seus serviços básicos oferecidos à própria população, para posteriormente oferecer aos turistas. Para isso foi preciso passar por momentos de tensão e conflitos referentes à pressão sofrida pela população durante os dias do festival, até se chegar a acordos sobre as metas para os eventos em níveis local, 
nacional e internacional e trabalhar para realizá-los. Assim, políticas públicas de interesse do Estado e da comunidade foram desenvolvidas, possibilitando alternativas para melhorar a infraestrutura básica da localidade, como saúde, educação, segurança, opções de lazer entre outras, num maior esforço para a qualidade de vida da população e qualidade nos serviços para os turistas.

No caso de Parintins (AM), o envolvimento da comunidade local na preparação e planejamento do festival folclórico mostra a importância que os eventos de caráter regional têm para as localidades. Em grande medida essas manifestações são promotoras do desenvolvimento local, ao passo que benefícios são promovidos para a comunidade. Em Parintins além da geração de renda e emprego, os espaços onde se concentram as apresentações dos Bois Garantido e Caprichoso ao final do espetáculo se transformam durante o restante do ano em uma escola de artes, a população pode utilizar daquele espaço para se beneficiar das formas de ensino das artes que são disponibilizadas. Durante o Festival, é notório o movimento de criação e re-apropriação da festa e do Festival pelos habitantes, que anualmente se reforça em laços comunitários, mesmo com a turistificação da festa.

Finalmente pode-se perceber que a relação entre desenvolvimento local, turismo e eventos culturais é extremamente enriquecedora, principalmente para os destinos turísticos que estão buscando nos eventos uma forma de promover a atividade turística, assim como um elemento de minimização de impactos da sazonalidade. A geração de emprego, renda e melhoria na infraestrutura das cidades são características fortes desses eventos, no entanto, também é preciso valorizar os atores locais dessa relação, a comunidade, pois nesse processo de apropriação do espaço, ela deve ter tal parcela de benefícios, haja vista que o visitante está ali por poucos dias e o morador necessita de benefícios de longo prazo, logo se entende que respeitadas essas variáveis, os eventos podem ser utilizados como ferramentas de desenvolvimento dos destinos turísticos e a coerência dessa relação implica na realização das principais variáveis concernentes ao desenvolvimento sustentável e ao desenvolvimento local.

\section{Referências bibliográficas}

AMORIM, C. G.. Redes Interorganizacionais e Captação de Eventos. In: BAHL, M. (Org.). Eventos: a importância para o turismo do terceiro mundo. São Paulo: Roca, 2003.

AZEVEDO, F.F.; FIGUEIREDO, S.L.; NÓBREGA, W.R.M.; MARANHÃO, C. H.S.Turismo em Foco: globalização e políticas públicas. In AZEVEDO, F.F. et al.(Org.). Turismo em Foco. Belém: NAEA, 2013,p. 11-27.

BRASIL. Ministério do Turismo. Eventos Internacionais no Brasil: resultados 2003 - 2009 desafios pra 2020. Brasília, DF: MTUR, 2010.

BRASIL. Ministério do Turismo. Plano Nacional de Turismo 2013-2016. Brasília, DF: MTUR, 2013.

BRITTO,J. FONTES, N.. Estratégias para eventos: uma ótica do marketing e do turismo. São Paulo: Aleph, 2002. 
Censo - $\quad$ Parintins. Disponível em: http://www.cidades.ibge.gov.br/xtras/perfil.php?lang=\&codmun=130340\&sear ch=amazonas|parintins. Acesso em junho de 2014.

COCA-COLA BRASIL. Disponível em: $<$ http://cocacolabrasil.com.br/imprensa/release/coca-cola-brasil-cria-acoespara-o-publico-e-investe-em-sustentabilidade-no-centenario-de-parintins/>. Acesso em 06/02/2014.

EMPRESA ESTADUAL DE TURISMO DO AMAZONAS - AMAZONASTUR. Pesquisa Socioeconômica - Festival Folclórico de Parintins 2005-2012.

EMPRESA ESTADUAL DE TURISMO DO AMAZONAS - AMAZONASTUR. PesquisaSocioeconômica- Festival Folclórico de Parintins 2005-2014.

FIGUEIREDO, S. L.; TAVARES, A. E. P. Mestres da Cultura. Belém: Editora da UFPA, 2006.

FRANCO, A.; DANTAS, C.; SILVA, D.; SALES, F.; DIAS, M. L.; GALVÃO, P.; LIMA, P.; CARVALHO, R.. Eventos, Cultura Popular e Memória Regional. In BAHL, M. (Org.). Eventos: a importância para o turismo do terceiro mundo. São Paulo: Roca, 2003.

FORTUNATU, R.A.; NEFFA, E. Abordagem Complexa e Desenvolvimento Local por meio do TurismoSolidário: o caso da rede "Brasilidade Solidária". Revista Turismo em Análise, Vol. 25, 2014, p. 51-74

GETZ, D. Eventos. In: LOHMANN, G.; PANOSSO NETO, A. Teoria do Turismo: conceitos, modelos e sistemas. São Paulo: Aleph (Série Turismo), 2012.

MARTINS, S.R.O. Desenvolvimento Local: questões conceituais e metodológicas. Revista Internacional de Desenvolvimento Local, Vol. 3, 2002, 51-59.

MATIAS, M. Organização de Eventos: procedimentos e técnicas. $5^{\circ}$ ed. Barueri, SP: Manole, 2010.

OLIVEIRA, A.. A economia dos megaeventos: impactos setoriais e regionais. Revista Paranaense de Desenvolvimento, n.120, 2011, p.257-275.

Parintins/AM.

Disponível

em

$<$ http://www.manausmais.com.br/parintins/content/parintins hoje.asp $>$

Acesso em: 15 de setembro de 2014.

SACHS, I. Estratégias de transição para o século XXI: desenvolvimento e meio ambiente. São Paulo: Studio Nobel,1993, p. 11-56.

SECRETARIA DE ESTADO DE CULTURA DO AMAZONAS - SEC. Relatório do Festival Folclórico de Parintins, 2010- 2012.

SECRETARIA DE ESTADO DE CULTURA DO AMAZONAS - SEC. Relatório do Festival Folclórico de Parintins, 2010- 2014.

SOUZA, N.D. 0 processo de urbanização da cidade de Parintins (AM): evolução e transformação. São Paulo:USP, 2013. Tese de Doutorado.

TOMAZZONI, E. L.. Turismo e desenvolvimento regional: dimensões, elementos e indicadores. Caxias do Sul, RS: Educs, 2009. 
VALENTIM, A. Contrários: A celebração da rivalidade dos Bois-Bumbás de Parintins. Manaus. Editora Valer, 2005.

\section{Nota:}

${ }^{1}$ Bolsista da Fundação de Amparo à Pesquisa do Estado do Amazonas FAPEAM.

${ }^{2}$ Entrevista com o Gerente de Eventos do Interior, Departamento de Eventos, em pesquisa no mês de fevereiro de 2014

José Jailson Medeiros de Melo: Universidade Federal do Rio Grande do Norte, Natal, RN, Brasil.

E-mail: jailsonmedeirosmelo@yahoo.com.br.

Link para o currículo Lattes: http://lattes.cnpq.br/3364809124270285

Ana Paula Araújo-Maciel: Universidade Federal do Rio Grande do Norte, Natal, RN, Brasil.

E-mail: anapaulinhapj@hotmail.com.

Link para o currículo Lattes: http://lattes.cnpq.br/1744709339481514

Silvio José de Lima Figueiredo: Universidade Federal do Pará, Belém, PA, Brasil.

E-mail: slima@ufpa.br.

Link para o currículo Lattes: http://lattes.cnpq.br/2578700144404800

Data de submissão: 01 de outubro de 2014

Data de recebimento de correções: 24 de abril de 2015

Data do aceite: 24 de abril de 2015

Avaliado anonimamente 